\title{
Levels and Sources of Atmospheric Polycyclic Aromatic Hydrocarbons Surrounding an Oil Refinery in Curaçao
}

\author{
Erin L. Pulster ${ }^{*}$, Giffe Johnson², Dave Hollander ${ }^{3}$, James McCluskey², Raymond Harbison ${ }^{2}$ \\ ${ }^{1}$ Mote Marine Laboratory, Sarasota, FL, USA \\ ${ }^{2}$ College of Public Health, University of South Florida, Tampa, FL, USA \\ ${ }^{3}$ College of Marine Science, University of South Florida, St. Petersburg, FL, USA \\ Email: *epulster@mail.usf.edu
}

How to cite this paper: Pulster, E.L., Johnson, G., Hollander, D., McCluskey, J. and Harbison, R. (2019) Levels and Sources of Atmospheric Polycyclic Aromatic Hydrocarbons Surrounding an Oil Refinery in Curaçao. Journal of Environmental Protection, 10, 431-453.

https://doi.org/10.4236/jep.2019.103025

Received: February 21, 2019

Accepted: March 16, 2019

Published: March 19, 2019

Copyright $\odot 2019$ by author(s) and Scientific Research Publishing Inc. This work is licensed under the Creative Commons Attribution International License (CC BY 4.0).

http://creativecommons.org/licenses/by/4.0/

\begin{abstract}
This research measured ambient levels of polycyclic aromatic hydrocarbons (PAHs) surrounding a petrochemical complex on the island of Curaçao using passive air sampling. In addition, source elucidation of PAHs was conducted using concentration profiles, distribution profiles, binary diagnostic ratios and factor analysis. Passive air samplers with polyurethane foam collection disks (PAS-PUFs) were deployed in $2011(n=43)$ and in $2014(n=30)$ to evaluate the extent of the emission plume as well as spatial and temporal differences in ambient PAH concentrations. In general, ambient PAH concentrations in Curaçao were consistent with other urban and industrialized regions of the world; however, the levels measured downwind of Isla Refineriá petrochemical complex were among some of the highest reported ambient PAHs globally. Ambient PAH concentrations ranged from 1.2 to $790 \mathrm{ng} / \mathrm{m}^{3}$ in 2011 and 27 to $660 \mathrm{ng} / \mathrm{m}^{3}$ in 2014, demonstrating no temporal differences. However, significant spatial differences were detected between samples collected upwind and downwind of the petrochemical complex. Significantly higher ambient PAH concentrations were found in the samples collected downwind of the petrochemical complex compared to those upwind in 2014 $(p<0.0001)$. Source elucidation revealed the ambient PAHs downwind were dominated by petrogenic emission sources and to a lesser degree pyrogenic emissions, whereas, the upwind locations appear to be equally influenced by both petrogenic and pyrogenic emissions sources.
\end{abstract}

\section{Keywords}

Petrochemical, Polycyclic Aromatic Hydrocarbons, Curaçao,

Passive Air Sampling, Diagnostic Ratios 


\section{Introduction}

Refinery operations have been associated with atmospheric emissions of a wide variety of criteria air pollutants (i.e. sulfur dioxides, nitrogen oxides, carbon monoxide and particulate matter), volatile organic components (i.e. benzene, toluene, ethylbenzene, m-xylene), hazardous air pollutants (i.e. polycyclic aromatic hydrocarbons, carbon monoxide, hydrogen cyanide, mercury), and other pollutants (i.e. greenhouse gases, hydrogen sulfide). The type and quality of the crude oil, refinery process and refined products all influence the variability, composition and amount of emissions from one refinery to another.

The presence of hydrocarbons (i.e. polycyclic aromatic hydrocarbons-PAHs) in the Wider Caribbean Region (WCR) is considered by UNEP to be a significant threat or potential risk factor to environmental and human health [1] [2]. Industrial point sources contribute $90 \%$ of the oil pollution loads entering the WCR coastal areas, mainly from approximately 100 oil refineries operating in this region [3]. One of the largest and oldest refineries in the WCR, Isla Refineriá, opened in 1918 and is located on the shores of Schottegat Bay within the densely populated capital of Willemstad, Curaçao. Although, the refinery was considered obsolete in the mid-1980s, it is still in use today with an operating capacity of $\sim 330,000$ barrels per day (http://www.refineriaisla.com) yet it has not been able or required to comply with environmental standards and permit requirements [4].

A legacy of human health and environmental issues is the basis of a historical debate and conflict between the public and local government of Curaçao. Using a survey questionnaire, communities downwind of Isla Refineriá and the major thoroughfare circling the refinery and the bay, Schottegatweg Ring, are reported to experience higher than average frequencies of headaches, nausea, chronic lung ailments, asthma and cancer [5]. The major unresolved dispute in Curaçao is whether the petrochemical emissions are solely due to motor vehicle emissions or whether the major contribution comes from one of the largest oil refineries in the WCR, Isla Refineriá [6]. There is no question that motor vehicular emission (MVE) has become an increasingly dominant contributor to air pollution globally [7]. The adverse health effect associated with elevated exposures to MVEs near busy roadways has emerged as a public health concern [7] [8]. A lack of concrete data makes it difficult to assess the source and impact of atmospheric PAHs from both motor vehicle traffic and refinery emissions.

In many cases it is difficult to determine direct causality with one particular constituent of air pollution (PM, sulfur dioxide, carbon monoxide, VOCs, etc.) due to its complexity and multiple sources, such as traffic and industrial and refinery operations. More than $98 \%$ of air pollution in urban settings are gases or vapor-phase compounds such as carbon monoxide and non-methane hydrocarbons. Due to these complexities, the objectives of this study were to quantify levels of atmospheric polycyclic aromatic hydrocarbons (PAHs) and to apply a variety of source identification techniques to evaluate the extent of pollution and to 
elucidate the point source(s) on the island of Curaçao.

\section{Materials and Methods}

\subsection{Site Selection and Study Design}

Curaçao is part of the Leeward Antilles in the southern Caribbean, 66 kilometers $(\mathrm{km})$ off the Venezuelan coast (Figure 1). It is currently considered a constituent country of the Kingdom of the Netherlands since its dissolution in 2010 from the Netherland Antilles. Curaçao is located in the Southern Caribbean Dry Zone characterized by a semi-arid to arid climate, with a distinguishable dry and rainy season, sustained easterlies and an average yearly temperature of $27^{\circ} \mathrm{C}$. The island is approximately $59 \mathrm{~km}$ in length, $4-11 \mathrm{~km}$ wide and a total land mass area of $\sim 444 \mathrm{~km}^{2}$. The population of $\sim 150,000$ (2018 estimate,

http://www.cia.gov) consists of greater than 50 nationalities with Dutch and Papiamento as the official languages. The majority of the population $(\sim 144,000$; 2018 estimate, http://www.cia.gov) resides in Willemstad, which is home to the Isla Refineriá petrochemical complex.

The site selections and designs varied between 2011 and 2014. The site selections in 2011 were specifically designed to address the extent of the emissions, whereas in 2014, the site selections were designed to evaluate spatial trends to between areas located upwind and downwind of the petrochemical complex. To

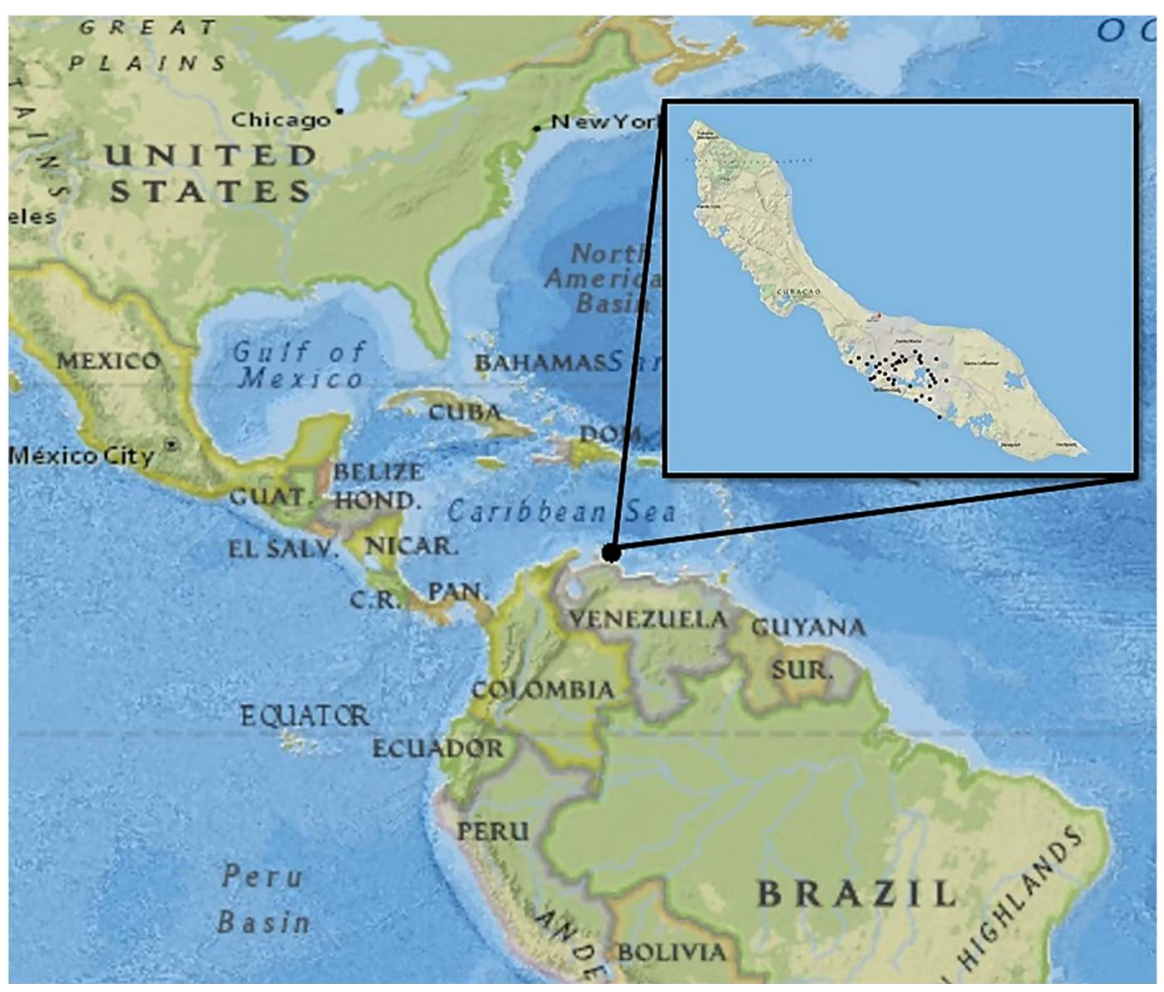

Figure 1. The island of Curaçao is located in the southern Caribbean off the coast of Venezuela. The inset of the island highlights the site locations (black dots $\bullet$ ) where the passive air samplers were deployed in 2011 and 2014. These site locations are further expanded in Figure 2. 
address the extent of the emissions, 15 sites were selected in 2011 based on their proximity to Isla Refineriá, Schottegatweg Ring, and along westerly transects from the ring outward to approximately $6 \mathrm{~km}$ west (downwind) of the refinery (Figure 2, See Pulster [9] for coordinates). PAS-PUFs were deployed in the general path determined by yearly average wind distribution plots in Curaçao (Figure 2). In 2014, 30 sites were selected around the entire Schottegatweg Ring including upwind $(n=15)$ and downwind $(n=15)$ locations from the petrochemical complex to address spatial trends (Figure 2, See Pulster [9] for coordinates). In both 2011 and 2014, the three major communities (Heintje Kool/Buena Vista, Marchena/Wishi, Habaai) involved in the 1999 Environmental Service of Curaçao Health Assessment were included in this study [5]. This 1999 assessment was conducted as a result of health complaints from communities directly exposed to refinery emissions.

\subsection{Passive Air Samplers (PAS-PUF)}

Polyurethane foam (PUF) collection substrates (P/N TE-1014; $1.27 \mathrm{~cm}$ thick $\times$ $13.97 \mathrm{~cm}$ diameter; density $0.029 \mathrm{~g} / \mathrm{cm}^{3}$ ) were purchased from Tisch Environmental (Village of Cleves, OH, USA). Prior to deployment, PUFs were individually packed

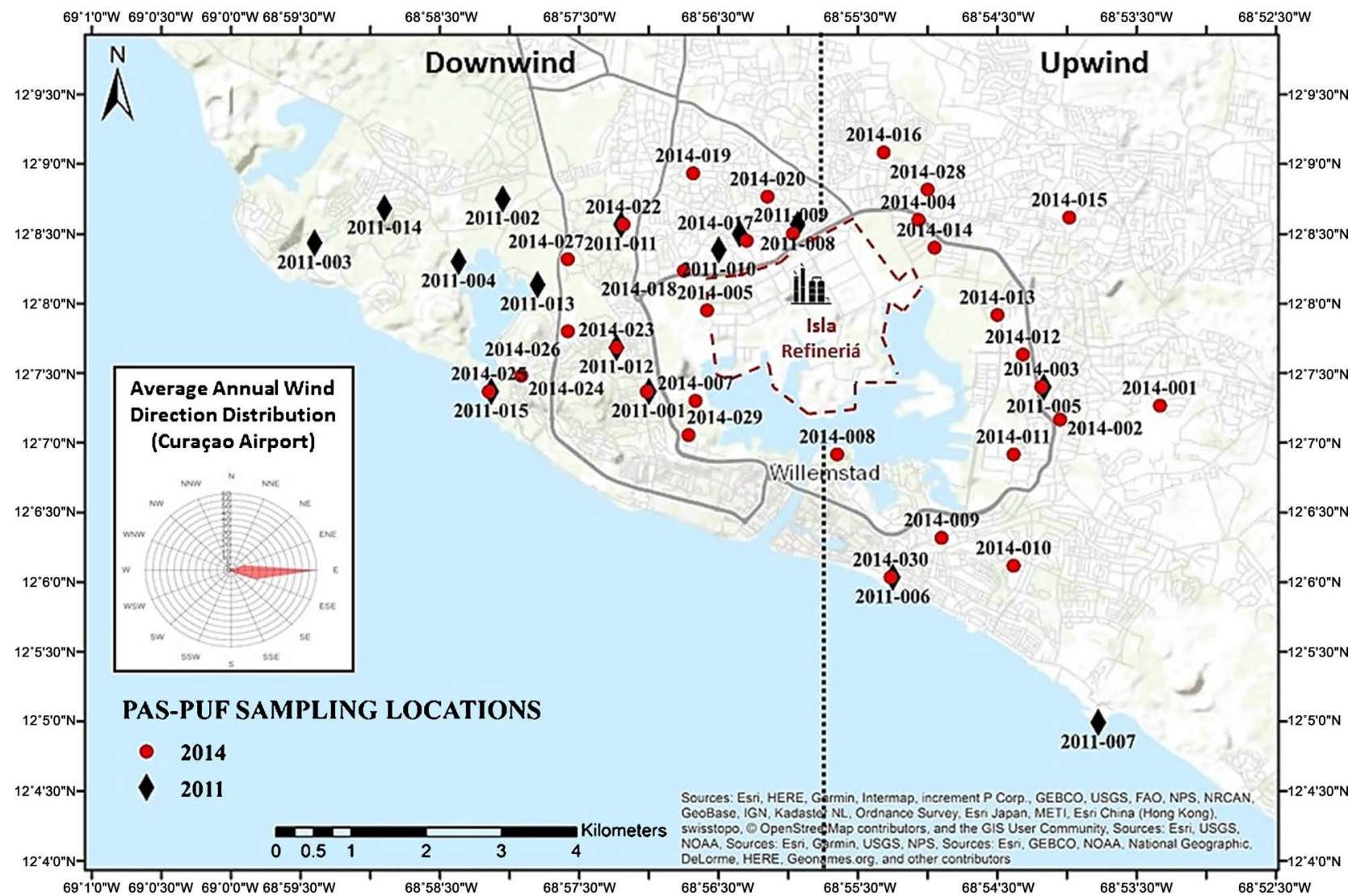

Figure 2. Ambient PAS-PUF sampling locations in Curaçao during the 2011 ( black diamonds) and 2014 (• red circles) sampling events. Samples collected downwind of the main petrochemical complex, Isla Refineriá (indicated by the dashed red line), are those to the left (or west) of the dotted black line. The samples collected upwind are those to the right (or east) of the dotted black line. The wind rose indicates the average year round easterly direction of the trade winds in Curaçao. 
into a $66 \mathrm{~mL}$ extraction cell and pre-cleaned with acetone and hexane using an Accelerated Solvent Extractor (ASE 300, Dionex, Sunnyvale, CA, USA). The ASE was programmed for three sequential cycles with the temperature of $100^{\circ} \mathrm{C}$, pressure of $1500 \mathrm{psi}$, static time of $5 \mathrm{~min}$, and a $60 \%$ flush volume, and a purge time of 60 seconds.

These pre-cleaned PUF vapor collection substrates were then sealed in solvent rinsed aluminum foil and in air tight containers to avoid contamination during transit to the island and sampling locations. The PUFs were suspended within dome-type passive air samplers (PAS-PUF) and deployed in triplicate at each of the 15 sites in 2011, with the exception of one site (Parasasa) deployed in duplicate $(n=43)$. Two of the triplicates were lost during processing from the Marie Pampoen site; therefore the concentration is based on a single sample. In 2011, samplers were deployed for $\sim 9$ weeks (65 \pm 1 day) from 28 February-6 May, 2011. Based on the 2011 triplicate precision and low variability measured by the mean relative standard deviation (10 \pm 5 \% RSD) between triplicates, the 2014 PAS-PUFs were deployed individually at 30 sites around Schottegatweg Ring for 9 weeks (63 \pm 1 day) from 13 May-18 July. At the end of each of the deployment periods, the PASs were retrieved and the PUFs were resealed and transported back to Mote Marine Laboratory where they were stored at $-20^{\circ} \mathrm{C}$ until analysis.

\subsection{PUF Extractions and Analysis}

The 2011 triplicate PUFs from each of the 15 sites $(n=43)$ and the 2014 PUFs $(n$ =30) were extracted and analyzed separately. Individual PUFs were placed into a $66 \mathrm{~mL}$ stainless steel accelerated solvent extraction (ASE) cell and spiked with deuterated PAH surrogate standards (naphthalene- $\mathrm{d}_{8}$, acenaphthene- $\mathrm{d}_{10}$, anthracene- $d_{10}$, benzo[a] anthracene- $d_{12}$, perlyene- $d_{12}$ ) and ortho-terphenyl (OTP) to monitor recoveries and validate the extraction and clean-up procedures. Each PUF was extracted using $100 \%$ methylene chloride $\left(\mathrm{CH}_{2} \mathrm{Cl}_{2}\right)$ under the same ASE conditions as above. The PUF extracts $(\sim 80 \mathrm{~mL})$ were reduced to $\sim 1-2 \mathrm{~mL}$ using a RapidVap (Labconco Corp., Kansas City, MO, USA) and eluted through an automated GPC system (Fluid Management Systems, Watertown, MA, USA) to remove high molecular weight interferences. For further cleanup and separation of polycyclic aromatic hydrocarbons (PAHs), the extract was then eluted with 80:20 $\mathrm{CH}_{2} \mathrm{Cl}_{2} /$ hexane (v/v) through a neutral silica column (6 g) using a multi-column clean-up system (Automated Power-Prep System, Fluid Management Systems, Watertown, MA, USA). The eluted fraction containing compounds of interest were collected and reduced to $900 \mathrm{uL}$ of methylene chloride.

Prior to instrument analysis, all extracts were spiked with two deuterated PAH internal standards (dibenzothiophene- $\mathrm{d}_{8}$, benzo[e]pyrene- $\mathrm{d}_{12}$ ) for quantification of targeted analytes. Extracts ( $1 \mu \mathrm{L}$ injection volume) were analyzed for approximately 61 polycyclic aromatic hydrocarbons (21 parent PAHs and homologues), using combined gas chromatography/mass spectrometry (GC/MS; Agilent 7890A/5975C; Agilent Technologies, Inc., Andover, MA, USA). Analyte se- 
paration was achieved on a DB-5MS capillary column $(30 \mathrm{~m} \times 0.25 \mu \mathrm{m}$ film thickness $\times 0.25 \mathrm{~mm}$ i.d.; Agilent Technologies, Inc., Andover, MA, USA) with ultrahigh-purity helium as the carrier gas. PAHs were determined in electron impact scan mode (EI) with helium as the carrier gas at $1 \mathrm{~mL} / \mathrm{min}$. The injector (splitless mode) and transfer line temperatures were set to $300^{\circ} \mathrm{C}$ and $280^{\circ} \mathrm{C}$, respectively. The oven temperature program was as follows: $60^{\circ} \mathrm{C}(0.5 \mathrm{~min}$ hold $)$, then $8^{\circ} \mathrm{C} / \mathrm{min}$ to $325^{\circ} \mathrm{C}$ ( 3 minute hold) for a total run time of 36.6 minutes. The source and quadrapole temperatures were set to $230^{\circ} \mathrm{C}$ and $150^{\circ} \mathrm{C}$, respectively. All mass spectral data were compared to spectra produced by authentic standards and to previously published library spectra.

\subsection{Calculated Air Concentrations}

Passive air samplers adsorb chemical constituents that can be used to assess ambient concentrations in the atmosphere. The extent to which chemicals are enriched in the sampling substrate relative to air is dependent on the passive sampler medium (PSM), or the air partition coefficient $\left(K_{P S M-A}\right)$. The PAS-PUF uptake of a chemical from the ambient air is best described by the effective concentration gradient between the air and the sampler following the equation:

$$
V_{S} \frac{\mathrm{d} C_{S}}{\mathrm{~d} t}=k_{O} A_{S}\left(C_{A}-\frac{C_{S}}{K_{S A}}\right)
$$

where $V_{s}$ is the sampler volume, $C_{s}$ is the analyte concentration in sampler, $C_{A}$ is the air concentration of the analyte, $k_{O}$ is the overall mass transfer coefficient, $A_{s}$ is the sampler surface area, and $K_{S A}$ is the sampler air/partitioning coefficient [10] [11]. The $K_{P S M-A}$ and the sampling rates (R) are both necessary to know in order to use PAS semi-quantitatively to assess ambient atmospheric concentrations and both have been previously calculated from field calibration experiments [12] [13]. Compound specific sampling rates were selected from calibration studies performed in a similar tropical environment [14]. Ambient air concentrations $\left(\mathrm{C}_{\text {air }} ; \mathrm{ng} / \mathrm{m}^{3}\right)$ in Curaçao were then calculated using compound specific sampling rates [14] in the Global Atmospheric Passive Sampling Network's template [12] for calculating air volumes for PAHs as follows:

$$
V_{\text {air }}=\left(K_{P S M-A}^{\prime}\right) \times\left(V_{P S M}\right) \times\left(1-\exp \left[\frac{k_{A}}{K_{P S M-A}^{\prime}} \times \frac{1}{D_{\text {film }}}\right] t\right)
$$

where $K_{P S M-A}^{\prime}$ takes into account the passive sampling medium octanol air partitioning coefficient $\left(\log K_{O A}\right)$ and is calculated by multiplying $K_{P S M-A}$ by the density of the PSM $\left(\mathrm{g} / \mathrm{m}^{3}\right), V_{P S M}$ is the volume of the passive sampling medium $\left(\mathrm{m}^{3}\right), k_{A}$ is the air-side mass transfer coefficient $(\mathrm{m} / \mathrm{d})$, which is equal to the sampling rate $\left(\mathrm{m}^{3} /\right.$ day) divided by the surface area of the PUF sampler ( 365 $\left.\mathrm{cm}^{2}\right), \mathrm{D}_{\text {film }}$ is the effective film thickness $(\mathrm{m})$, and $t$ is the deployment time (days), $m_{i}$ is the mass of the target analyte measured in the passive samples (ng/disk). 


\subsection{Source Characterization}

Concentration and distribution profiles, binary diagnostic ratios and factor analyses were used to characterize sources of ambient PAHs in Curaçao. Concentration and distribution profiles were used to differentiate between petrogenic and pyrogenic sources by evaluating the distribution of the parent compounds and their homologues. Binary diagnostic ratios were evaluated to differentiate between vehicular and non-traffic emissions, diesel and gasoline combustion, different crude oil processing and biomass burning. Each of the diagnostic approaches has its limitations and uncertainties, therefore it is highly recommended to interpret more than one ratio to identify and confirm a source(s). Therefore, in this study, 10 different ratios were evaluated to elucidate potential sources, however sites with non-detects of both binary ratio compounds were excluded from the analysis. To prevent biases, ratios where one of the compounds was below the detection limit, resulting in a ratio of either 0 or 1 , were considered to be less than the instrument detection limit $(<\mathrm{IDL})$ and were not included in the analysis. A total of six binary ratios of PAH pairs were further evaluated herein (Table 1).

Factor analysis and principal components analysis (PCA) were also used to analyze all sources of variability in the dataset by transforming and reducing the number of correlated variables into principal components that account for the majority of the variability. Within the factors, each variable is assigned a factor loading which determines the most representative indicator PAH. The level of significance for the factor loadings is generally determined by the relationship between the loadings and the magnitude of the sample size [15] [16] [17]. Nevertheless, the general rule of thumb is that the loadings should be at least 0.70 [18], however in this study, we chose a more stringent value of $>0.80$ for increased robustness. The grouped variables or factors are then interpreted as specific emission sources that are characterized by the most representative indicator $\mathrm{PAH}(\mathrm{s})$ [19]. In this study, only detectable levels of the parent PAH compounds from the 2014 downwind sites (18 PAHs), 2014 upwind sites (15 PAHs) and the 2011 sites (18 PAHs) were input into the factor analysis and PCA. The fifteen stations sampled in triplicate in 2011 were combined since the sample size was too small to detect statistical differences $(p=0.43)$ between the upwind $(n=3)$ and downwind $(n=12)$ locations.

\subsection{Quality Assurance and Quality Control (QA/QC)}

A performance-based quality-assurance and quality-control program, including the parallel analysis of procedural blanks and matrix spikes was implemented to ensure data of the highest quality. Quality assurance and quality control guidelines follow TDI-Brooks International, B\&B Laboratories Inc., EPA 8270D and NOAA established criteria for PAH analysis. Five custom calibration standards ranging in concentration from 25 to $1000 \mathrm{ng} / \mathrm{mL}$ were used. Prior to sample analysis, the initial calibration passed the following established criteria: $R^{2}=0.99$ 
- 1 for all compounds and surrogates and the $\%$ RSD was $\leq 20 \%$ for all relative response factors. The GC response is monitored using a mid-level $(250 \mathrm{ng} / \mathrm{mL})$ continuing calibration standard, passing acceptable criteria (\% RSD $\leq 25 \%$ for $90 \%$ of the analytes; $\leq 35 \%$ for $10 \%$ of the analytes). Procedural blanks were checked to confirm they were clear of targeted analytes. Acceptable blanks were considered to contain no more than three times the MDL for two or more target analytes. The method of detection limit (MDL) is defined as three times the standard deviation of the mean concentration of each analyte detected in the blanks. Only two of the 21 parent PAHs were detected in the blanks (naphthalene and phenanthrene). The MDLs were 22 and 196 ng/PUF for naphthalene and phenanthrene, respectively. Instrument detection limits ranged from 0.06 to $0.24 \mathrm{ng} / \mathrm{mL}$. Calculated ambient PAH concentrations are reported at two significant figures in $\mathrm{ng} / \mathrm{m}^{3}$.

Sample analyte concentrations were quantified based on the concentration and response of the internal standards (dibenzothiophene- $\mathrm{d}_{8}$ and benzo[e]pyrene- $\mathrm{d}_{12}$ ). All samples and method blanks were spiked with OTP and four (4) deuterated PAH surrogate compounds (naphthalene- $\mathrm{d}_{8}$, acenaphthene- $\mathrm{d}_{10}$, anthracene- $\mathrm{d}_{10}$, benzo[a]anthracene- $d_{12}$, perlyene- $d_{12}$ ) prior to extraction. All samples passed the acceptable surrogate recovery criteria (\% recovery 50\% - 150\%). The mean recovery of OTP spiked in the 2011 samples was $104 \% \pm 6 \%$. The 2011 overall recovery for the low and high molecular weight surrogates were $61 \% \pm 11 \%$ and $84 \% \pm 9 \%$, respectively. The 2011 overall recovery for the matrix spiked with 18 parent PAHs was $82 \% \pm 25 \%$. The mean recovery of OTP spiked in the 2014 samples was $103 \% \pm 11 \%$. The 2011 overall recovery for the low and high molecular weight surrogates were $91 \% \pm 15 \%$ and $105 \% \pm 20 \%$, respectively. The 2014 overall recovery for the matrix spiked with 18 parent PAHs was $78 \% \pm 8 \%$. Individual and standard mixtures of PAHs were purchased from AccuStandard (New Haven, CT, USA).

\subsection{Data and Statistical Analysis}

Calculated ambient PAHs are expressed as $\mathrm{ng} / \mathrm{m}^{3}$. Non-detectable levels were not substituted with detection limits. Data were transformed (square root) to meet the assumptions of normality. In the event a normal distribution was justified, parametric statistics were performed using Student's t-tests and ANOVA to evaluate spatial and temporal differences $(\alpha=0.05)$ using JMP Pro Version 14.2.0 (SAS Institute, Inc.). Raw data were used to complete factor analysis and PCA using Statistica Version 6 (StatSoft Inc., Tulsa, OK, USA).

\section{Results and Discussion}

\subsection{Ambient Concentrations of Polycyclic Aromatic Hydrocarbons}

Calculated ambient concentrations of PAHs ranged from $1.2-790 \mathrm{ng} / \mathrm{m}^{3}$ and 27 - $660 \mathrm{ng} / \mathrm{m}^{3}$ during the 2011 and 2014 sampling events, respectively (Figure 3, see Pulster [9] forindividual PAH concentrations). There were no observable 


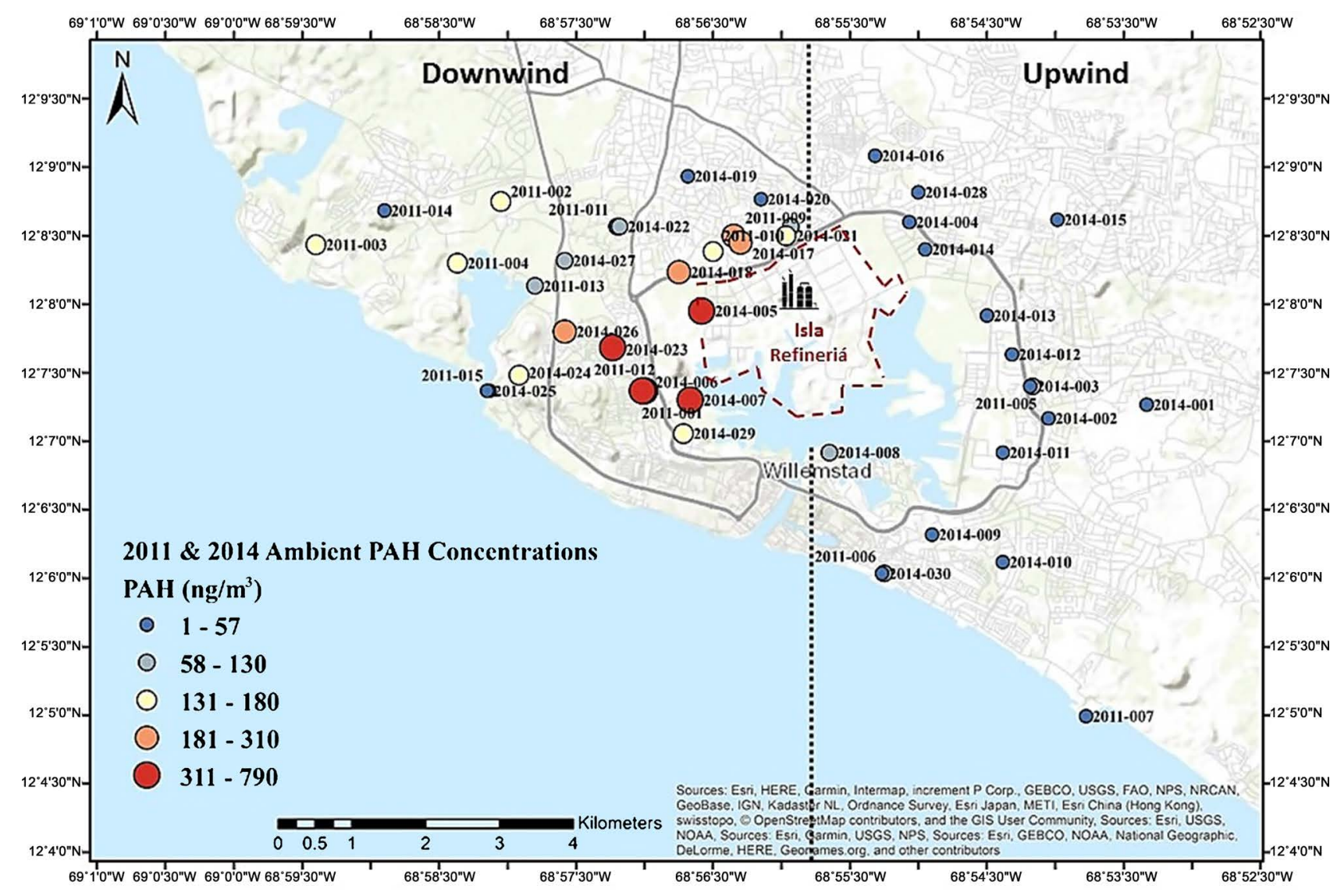

Figure 3. Calculated ambient PAH concentrations $\left(\mathrm{ng} / \mathrm{m}^{3}\right)$ in Curaçao from the 2011 and 2014 sampling events. Ambient PAH concentrations ranged from 1 to $790 \mathrm{ng} / \mathrm{m}$ with no significant temporal trends.

temporal trends or statistical differences between the 2011 and 2014 mean ambient $\sum$ PAHs $(p=0.81)$, $\sum$ LMW PAHs $(p=0.080)$ or the $\Sigma$ HMW PAHs $(p=$ $0.92)$ measured at sites located downwind of the Isla Refineria petrochemical complex in Curaçao (Figure 4). However, the $\Sigma$ LMW PAHs measured upwind in 2011 were marginally higher $(p=0.0434)$ than those measured upwind in 2014 (Figure 4).

The 2011 site selections were designed to evaluate the extent of emissions, therefore it is not surprising we were unable to detect differences between the upwind $(n=3)$ and downwind $(n=12)$ locations due to sample sizes. However, there was a weak negative correlation $\left(\mathrm{R}^{2}=0.20, p=0.096\right)$ between ambient $\mathrm{PAH}$ concentrations and increasing distance between the petrochemical complex, nevertheless, the lowest levels were measured in Blauw/Curasol (site $\# 2011-014 ; 1.2 \mathrm{ng} / \mathrm{m}^{3}$ ) which was one of the furthest sites west of the refinery ( 6 $\mathrm{km})$. Atmospheric PAHs were also detected in Boca Sami $\left(160 \mathrm{ng} / \mathrm{m}^{3} \Sigma \mathrm{PAH}\right)$ which is $\sim 7 \mathrm{~km}$ west of the refinery and was the western most site sampled during 2011. Levels were moderately elevated in Boca Sami considering the distance however, this site was the highest point sampled with an elevation of approximately 120 feet above sea level whereas the petrochemical complex sits at approximately 22 feet above sea level. Although the consistent easterly direction of 


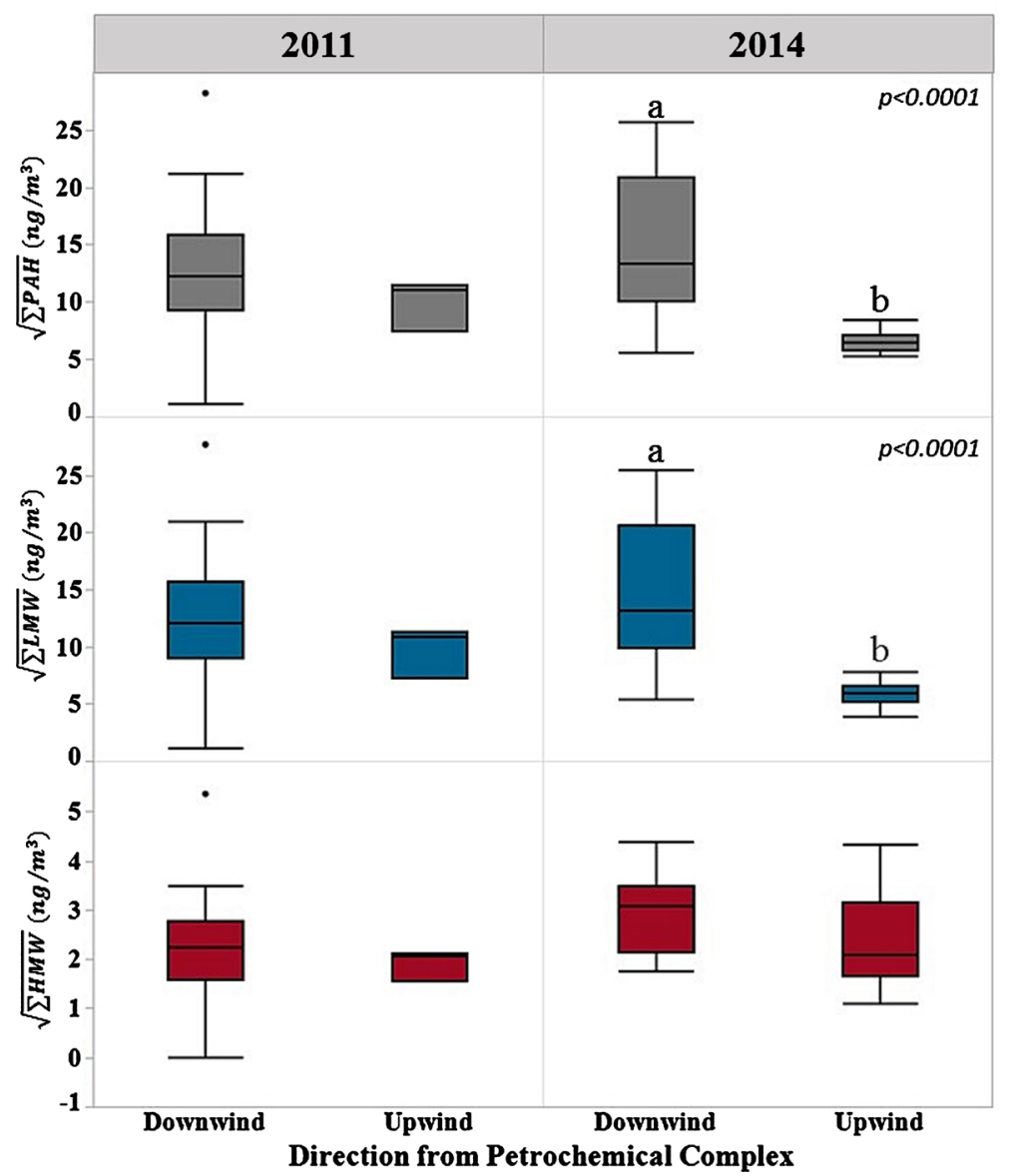

Figure 4. The square root $\left(\sqrt{ }\right.$ of ambient $\Sigma$ PAHs $\left(\mathrm{ng} / \mathrm{m}^{3}\right)$, low molecular weight ( $\Sigma \mathrm{LMW}$, $\mathrm{ng} / \mathrm{m}^{3}$ ) and high molecular weight ( $\mathrm{H} \mathrm{HMW}, \mathrm{ng} / \mathrm{m}^{3}$ ) PAHs by collection year and direction from the petrochemical complex, Isla Refineriá, in Curaçao. In 2014, locations downwind of the petrochemical complex (Isla Refineriá) had significantly higher levels of ambient $\sum$ PAHs $(p<0.0001)$ and $\sum$ LMW PAH $(p<0.0001)$ concentrations than those located upwind.

the Trade Winds is a critical factor in ambient levels and distribution of PAHs, the lack of correlations with increasing distance from the petrochemical complex and PAH levels could be attributed to the terrain elevation, physical geography and flux trajectories associated with wind speeds.

In 2011 the highest levels of PAHs were measured at the two sites directly downwind (Habaai site \#2011-001, $790 \mathrm{ng} / \mathrm{m}^{3}$; Marchena site \#2011-012, $450 \mathrm{ng} / \mathrm{m}^{3}$ ) of the Isla Refineriá petrochemical complex. These two sites located directly downwind of the petrochemical complex had concentrations significantly higher than all other sites, equaling one to two orders of magnitude higher than the eastern (upwind) and western (downwind) most sites, respectively. In particular, the PAH concentrations measured at Habaai (site \#2011-001) were over 600 times higher than those measured at Blauw/Curasol (2011-014; $1.2 \mathrm{ng} / \mathrm{m}^{3}$ ) and were almost 15 times higher than the most eastern or upwind site, Marie Pampoen (site \#2011-007; $55 \mathrm{ng} / \mathrm{m}^{3}$ ).

The calculated 2014 ambient PAH levels ranged from 31 to $660 \mathrm{ng} / \mathrm{m}^{3}$ and 27 
to $70 \mathrm{ng} / \mathrm{m}^{3}$ for the downwind and upwind sites, respectively. Similar to the 2011 sites, sites located downwind of the petrochemical complex [Welgelegen/Veld Salu (site \#2014-007; $660 \mathrm{ng} / \mathrm{m}^{3}$ ), Beth Haim/Marchena (site \#2014-005, 460 $\mathrm{ng} / \mathrm{m}^{3}$ ) Habaii (site \#2014-006, $440 \mathrm{ng} / \mathrm{m}^{3}$ ) had the highest ambient PAH levels in 2014. The 2014 stations were specifically selected to evaluate spatial trends. Measured ambient PAHs at stations located downwind ( $\tilde{X} \pm \sigma: 250 \pm 180$ $\mathrm{ng} / \mathrm{m}^{3}$ ) of the Isla Refineriá petrochemical complex and Schottegat Harbor had significantly higher $(p<0.0001)$ than those measured at the upwind sites ( $\tilde{x} \pm \sigma: 42 \pm 12 \mathrm{ng} / \mathrm{m}^{3}$; Figure 4). Ambient PAHs measured downwind of the petrochemical complex were up to two orders of magnitude higher than those measured upwind. These results are supported by previous studies evaluating other emission constituents (i.e. total suspended particulate, sulfate, chlorides, lead) which concluded the refinery affects a substantial portion of the western side of the island, and more so, those sites directly downwind of the refinery [9] [20] [21].

\subsection{Global Comparisons of Ambient PAH Concentrations}

In general, the ambient concentration of PAH levels in this study were consistent with other urban and industrial regions found globally, but up to three orders of magnitude higher than some remote and rural areas (Figure 5) [22]-[36]. The mean concentrations of ambient PAHs downwind of the Isla Refineriá petrochemical complex as well as those from select locations (Habaii, Welgelegen, Beth Haim, Marchena) located directly downwind were among some of the

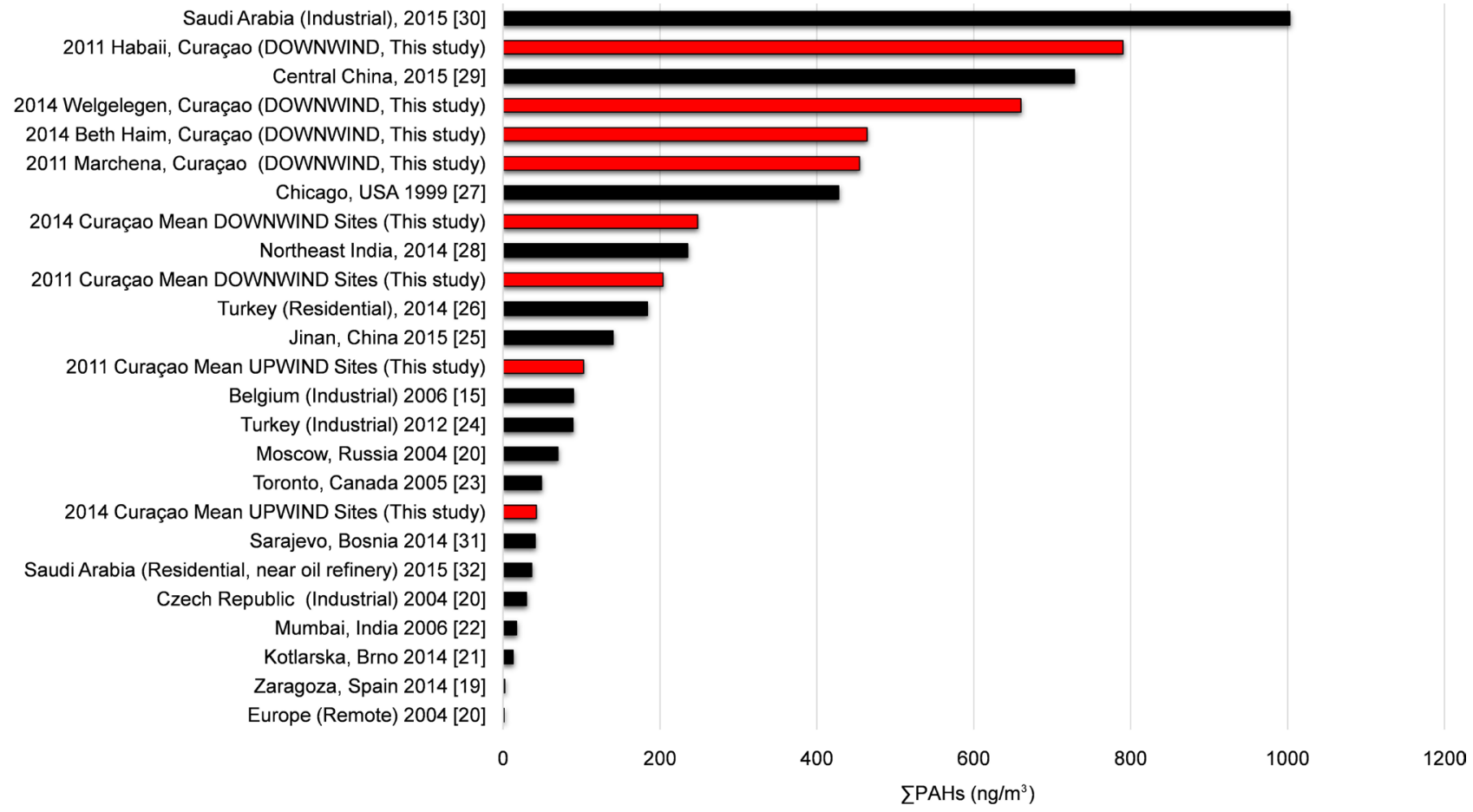

Figure 5. Global comparison of ambient PAH concentrations $\left(\mathrm{ng} / \mathrm{m}^{3}\right)$. Mean concentrations and select sites located downwind and upwind of a petrochemical complex in this study are represented by the red bars. 
highest reported ambient PAHs globally and were similar to the highly polluted capital city of Shaanxi Province in central China [32] as well as industrial regions of Saudi Arabia [33].

In comparison, the sites located upwind of Isla Refineriá were 33 times higher than some remote areas of Europe [23], yet almost 6 times lower than those measured downwind in this study and almost 24 times lower than the levels reported in Saudi Arabia [33]. Although the ambient PAHs measured upwind $\left(\tilde{x} \pm \sigma: 42 \pm 12 \mathrm{ng} / \mathrm{m}^{3}\right.$ ) of Isla Refineriá were substantially lower than those measured near industrial areas in Saudi Arabia, they were similar to those measured in other residential areas surrounding an oil refinery in Saudi Arabia and industrial regions of the Czech Republic, Belgium and Turkey [19] [23] [35].

\subsection{Source Characterization}

Identifying and understanding the impact of emission sources is critical for proper risk assessment and management [37]. The emission of PAHs is from a variety of anthropogenic sources which can be categorized as domestic sources, mobile sources, industrial and agricultural sources. Binary diagnostic ratios and $\mathrm{PAH}$ concentration profiles have been useful in identifying emission sources and their contributions to ambient air concentrations in order to distinguish between different sources, such as petrogenic, pyrogenic or phytogenic [19] [38] [39] [40]. PAHs originating from petrogenic sources primarily consist of the low molecular weight compounds having two or three fused benzene rings and an abundance of substituted PAHs (homologues with 2 - 3 alkyl carbons), thereby displaying a characteristic bell-shape with respect to the degree of alkylation [41] [42] [43] [44]. PAHs originating from pyrogenic sources primarily consist of the high molecular weight compounds having four to six fused benzene rings and dominated by the unsubstituted PAHs or homologues with $1-2$ alkyl carbons. Therefore, profiles from petrogenic sources display a characteristic bell-shape with increasing concentrations with increasing degree of alkylation $(\mathrm{C} 0<\mathrm{C} 1<$ $\mathrm{C} 2<\mathrm{C} 3<\mathrm{C} 4)$ whereas pyrogenic sources produce a decreasing concentration in the distribution within a homologue series $(\mathrm{C} 0>\mathrm{C} 1>\mathrm{C} 2>\mathrm{C} 3>\mathrm{C} 4)$ [42] [43].

Concentration and Distribution Profiles. In this study, ambient PAH concentrations were dominated by the low molecular weight (LMW) 2 - 3 ring PAH compounds, accounting for $97 \%$ and $96 \%$ of the compounds at the 2011 downwind and upwind sites, respectively (Figure 4 and Figure 6). Similarly, the LMW PAHs also accounted for $96 \%$ and $84 \%$ of the ambient PAH concentrations at the downwind sites and upwind sites in 2014, respectively. In petroleum refining, the 2 - 3 ring compounds account for approximately $94 \%$ of the PAHs [19]. This would indicate a strong petrogenic source and suggest the downwind locations may be highly influenced by the Isla Refineriá petrochemical complex.

The 2011 concentration distribution profiles illustrate both a petrogenic and pyrogenic signal (Figure 6). The profile for the upwind and downwind stations were both dominated by the low molecular weight compounds ( $2-3$ rings $)$ and 

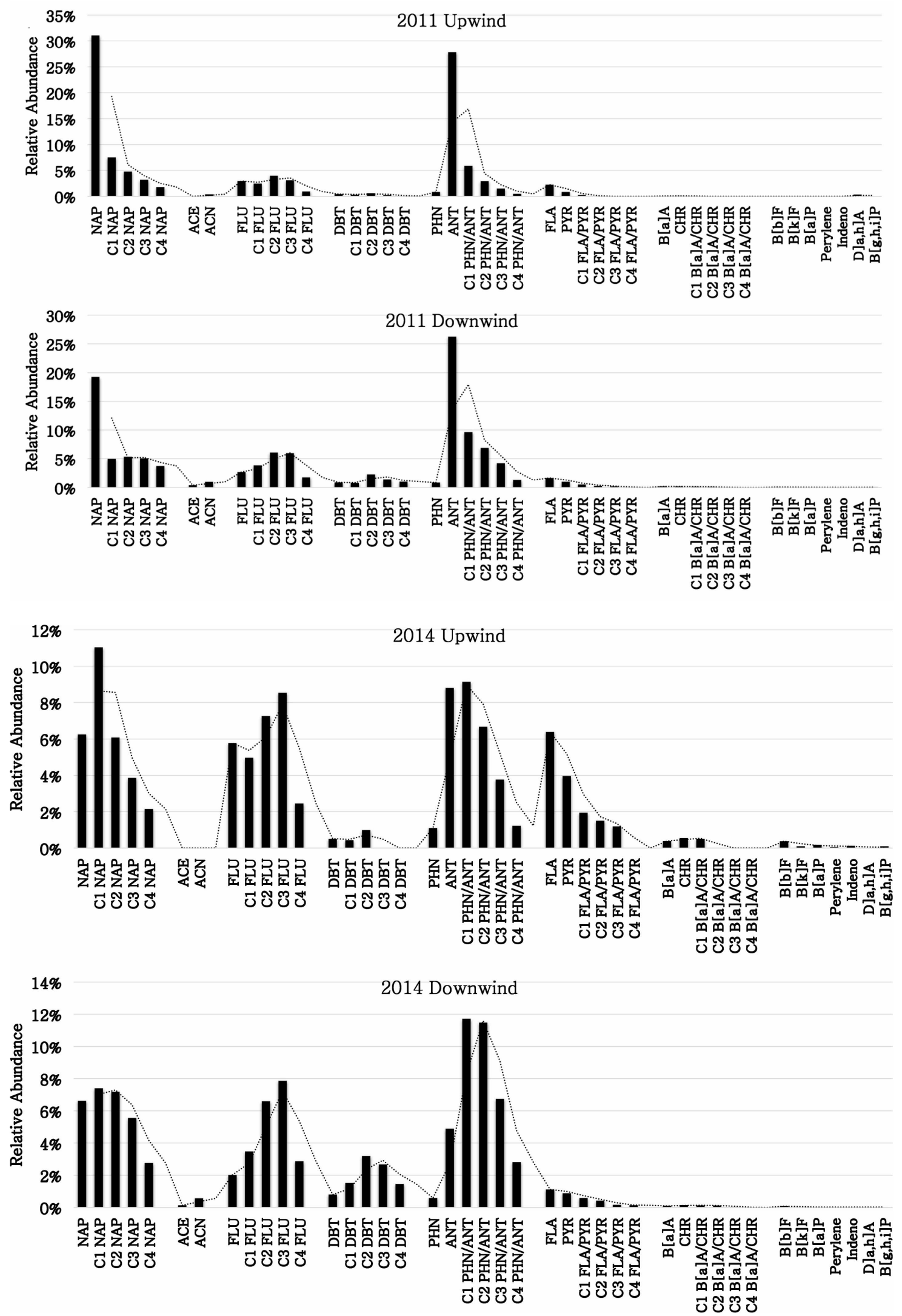

Figure 6. Concentration distribution profiles for ambient PAHs collected upwind and downwind of the Isla Refineriá petrochemical complex in Curaçao during 2011 and 2014. 
the fluorene (FLU) and dibenzothiophene (DBT) series demonstrate a classic bell-shape curve indicative of petrogenic sources, whereas, the naphthalene (NAP), phenanthrene/anthracene (PHN/ANT) and fluoranthene/pyrene (FLA/PYR) series were all dominated by the parent compound with decreasing concentration with increasing alkylation, indicative of a pyrogenic source. The 2014 downwind and upwind PAH profiles demonstrate a stronger petrogenic signal illustrated by the majority of LMW compounds ( 2 - 3 rings) and most of the homologue series illustrate the classic bell shape characteristic of petrogenic sources, with the exception of the FLA/PYR series (Figure 6).

Overall, the concentration profiles for both the 2011 and the 2014 upwind and downwind sites were all dominated by low molecular weight compounds suggesting a strong petrogenic source, while the distribution profiles also suggested a strong petrogenic signal and to a lesser extent, a pyrogenic signal.

Binary Diagnostic Ratios. Binary diagnostic ratios have been useful in identifying emission sources and their contributions to ambient air concentrations in order to distinguish between different sources, such as petrogenic (hydrocarbons associated with petroleum), pyrogenic (hydrocarbons associated with incomplete combustion) or phytogenic (hydrocarbons derived from plants) [19] [37] [45] [46]. Studies have been able to differentiate between vehicular and non-traffic emissions, diesel and gasoline combustion, different crude oil processing and biomass burning [19] [41] [47] [48] [49]. However, each of the diagnostic approaches has its limitations and uncertainties. For instance, the ratios of anthracene/(anthracene + phenanthrene) $[\mathrm{ANT} /(\mathrm{ANT}+\mathrm{PHE})]$ may be strongly influenced by photoreactions resulting in ratios close to 1 , whereas photoreactions can result in higher values for the fluoranthene/(fluoranthene + pyrene) [FLA/(FLA = PYR)] ratio [37] [50]. Consequently, more than one diagnostic ratio should be used to confirm the indicated source(s).

The PAH binary diagnostic ratios for the 2011 and 2014 air samples indicated a combination of both petrogenic and pyrogenic sources depending on the ratio (Table 1). Two (Blauw/Curasol site \#2011-014, and Parasasa site \#2011-015) of the 15 sites sampled in 2011 had non-detectable levels of the parental PAH diagnostic ratios and were therefore eliminated from the analysis. The low molecular weight to the high molecular weight compounds (LMW/HMW > 1 [47]), phenanthrene to phenanthrene plus anthracene $(\mathrm{PHN} /(\mathrm{PHN}+\mathrm{ANT})=\sim 0.98$ [45]) and the phenanthrene to anthracene (PHN/ANT > 10 [46]) from all the 2011 sites suggested a dominant petrogenic (i.e. petroleum, refinery) source. Fluoranthene to fluoranthene plus pyrene [FLA/(FLA+PYR) $>0.5$ [19] [36]] suggested a pyrogenic source of grass, wood or coal combustion $(>0.5)$ (Table 1). Fluoranthene to pyrene (FLA/PYR > 1 [45] [46]) also suggested a pyrogenic source mainly of coal combustion. The benzo[a]chrysene to benzo[a]chrysene plus chrysene $[\mathrm{BaA} /(\mathrm{BaA}+\mathrm{CHR})>0.35[47][48]]$ indicated combustion as a source. The additional four ratios $[\mathrm{BaP} /(\mathrm{BaP}+\mathrm{CHR})][\mathrm{IND} /(\mathrm{IND}+\mathrm{BghiP})]$ [IND/BghiP] [BaP/BghiP] are primarily used to discriminate between pyrogenic sources (i.e. gasoline vs diesel) however either one or both of the parent compounds 
Table 1. The 2011 and 2014 site specific binary diagnostic ratios used in this study to elucidate between petrogenic (petro) and pyrogenic (pyro) emission sources.

\begin{tabular}{|c|c|c|c|c|c|c|c|}
\hline Sample ID & Neighborhood & LMW/HMW & PHN/(PHN + ANT $)$ & PHN/ANT & FLA/(FLA + PYR) & FLA/PYR & $\mathrm{BaA} /(\mathrm{BaA}+\mathrm{CHR})$ \\
\hline 2011-001 & Habaai & 12 & 0.97 & 34 & 0.66 & 2.0 & 0.49 \\
\hline 2011-002 & Groot Piscadera & 14 & 0.97 & 35 & 0.67 & 2.0 & 0.56 \\
\hline 2011-003 & Boka Sami & 19 & 0.97 & 34 & 0.67 & 2.1 & 0.59 \\
\hline 2011-004 & W. Piscadera Baai & 47 & 0.97 & 37 & 0.68 & 2.1 & $<\mathrm{IDL}$ \\
\hline 2011-005 & Rooi Catochi & 22 & 0.98 & 54 & 0.67 & 2.7 & $<\mathrm{IDL}$ \\
\hline 2011-006 & Nieuw Nederland & 18 & 0.97 & 35 & 0.70 & 2.4 & 0.36 \\
\hline 2011-007 & Marie Pampoen & 17 & $<\mathrm{IDL}$ & $<\mathrm{IDL}$ & 0.77 & 3.4 & $<\mathrm{IDL}$ \\
\hline 2011-008 & Buena Vista & 9.4 & 0.96 & 23 & 0.66 & 2.0 & $<\mathrm{IDL}$ \\
\hline 2011-009 & Buena Vista & 33 & 0.97 & 32 & 0.64 & 1.8 & 0.44 \\
\hline 2011-010 & Heintje Kool & 10 & 0.97 & 29 & 0.64 & 1.8 & 0.36 \\
\hline 2011-011 & Roosendaal & 12 & 0.97 & 31 & 0.66 & 2.0 & $<\mathrm{IDL}$ \\
\hline 2011-012 & Marchena/Wishi & 13 & 0.96 & 26 & 0.62 & 1.6 & 0.40 \\
\hline 2011-013 & E. Piscadera Baai & 10 & 0.97 & 31 & 0.65 & 1.8 & 0.21 \\
\hline 2011 Mean & ratio and Dominant Source & $\begin{array}{c}17 \\
(\text { Petro > 1) }\end{array}$ & $\begin{array}{c}0.97 \\
(\text { Petro } \sim 0.98)\end{array}$ & $\begin{array}{c}33 \\
(\text { Petro }>10)\end{array}$ & $\begin{array}{c}0.70 \\
(\text { Pyro }>0.5)\end{array}$ & $\begin{array}{c}2.1 \\
(\text { Pyro > 1) }\end{array}$ & $\begin{array}{c}0.43 \text { (Pyro > } 0.35-0.5 \\
\text { vehicle combustion) }\end{array}$ \\
\hline 2014-001 & Toni Kunchi & 5.6 & 0.92 & 12 & 0.71 & 2.5 & 0.38 \\
\hline 2014-002 & Groot Davelaar/Joonchi & 9.9 & 0.88 & 7.6 & 0.68 & 2.2 & 0.42 \\
\hline 2014-003 & Rooi Catochi & 0.18 & $<\mathrm{IDL}$ & $<$ IDL & 0.66 & 1.9 & 0.40 \\
\hline 2014-004 & Emmastad & 0.66 & 0.87 & 8.0 & 0.60 & 1.4 & 0.45 \\
\hline 2014-005 & Beth Haim (Marchena) & 11 & 0.89 & 9.1 & 0.52 & 1.1 & 0.37 \\
\hline 2014-006 & Habaai & 3.5 & 0.90 & 9.3 & 0.57 & 1.3 & 0.37 \\
\hline 2014-007 & Welgelegen (Veld Salu) & 10 & 0.89 & 7.7 & 0.39 & 0.65 & 0.25 \\
\hline 2014-008 & Punda & 2.6 & 0.95 & 21 & 0.65 & 1.9 & 0.34 \\
\hline 2014-009 & Pietermaai/Salina & 0.66 & 0.88 & 7.2 & 0.59 & 1.4 & 0.40 \\
\hline 2014-010 & Steenrijk & 1.7 & 0.92 & 11 & 0.65 & 1.9 & 0.38 \\
\hline 2014-011 & Zeelandia & 3.7 & 0.85 & 5.7 & 0.61 & 1.6 & 0.47 \\
\hline 2014-012 & Rooi Catochi & 5.1 & 0.87 & 6.6 & 1.0 & $<\mathrm{IDL}$ & 0.47 \\
\hline 2014-013 & Biesheuvel & 3.4 & 0.87 & 6.6 & 0.61 & 1.6 & 0.51 \\
\hline $2014-014$ & Emmastad & 1.4 & 0.87 & 6.7 & 0.60 & 1.5 & 0.45 \\
\hline 2014-015 & Brievengat/Groot Kwartier & 1.6 & $<\mathrm{IDL}$ & $<\mathrm{IDL}$ & 0.65 & 1.8 & 0.32 \\
\hline 2014-016 & Suffisant & 3.6 & 0.83 & 4.8 & 0.65 & 1.9 & 0.40 \\
\hline 2014-017 & Buena Vista & 7.6 & 0.86 & 9.1 & 0.51 & 1.0 & 0.37 \\
\hline 2014-018 & Buena Vista & 6.7 & 0.89 & 8.4 & 0.58 & 1.4 & 0.45 \\
\hline 2014-019 & Wanapa & 2.1 & 0.81 & 4.2 & 0.62 & 1.6 & 0.45 \\
\hline 2014-020 & Buena Vista & 4.2 & 0.86 & 6.2 & 0.64 & 1.8 & 0.43 \\
\hline 2014-021 & Buena Vista & 14 & 0.86 & 6.1 & 0.58 & 1.4 & 0.42 \\
\hline
\end{tabular}




\begin{tabular}{|c|c|c|c|c|c|c|c|}
\hline \multicolumn{8}{|c|}{ Continued } \\
\hline 2014-022 & Roosendaal (Peroweg) & 2.2 & 0.94 & 15 & 0.63 & 1.7 & 0.40 \\
\hline 2014-023 & Marchena & 7.3 & 0.89 & 7.9 & 0.52 & 1.1 & 0.39 \\
\hline 2014-024 & Parasasa (Piscaderaweg) & 4.9 & 0.89 & 8.3 & 0.58 & 1.4 & 0.41 \\
\hline 2014-025 & Parasasa & 2.4 & 0.91 & 10 & 0.56 & 1.3 & 0.35 \\
\hline $2014-026$ & Wishi & 9.2 & 0.89 & 8.4 & 0.55 & 1.2 & 0.41 \\
\hline $2014-027$ & Gasparitu (Roosendaal) & 5.6 & 0.90 & 9.4 & 0.59 & 1.5 & 0.42 \\
\hline 2014-028 & Suffisant & 3.9 & 0.88 & 7.1 & 0.62 & 1.6 & 0.42 \\
\hline 2014-029 & Domi/Welgelegen & 6.8 & 0.89 & 8.0 & 0.60 & 1.5 & 0.37 \\
\hline 2014-030 & Nieuw Nederland & 2.6 & $<$ IDL & $<\mathrm{IDL}$ & 0.64 & 1.8 & 0.50 \\
\hline \multicolumn{2}{|c|}{$\begin{array}{l}2014 \text { Mean Downwind Ratios } \\
\text { and Dominant Source }\end{array}$} & $\begin{array}{c}6.7 \\
(\text { Petro }>1)\end{array}$ & 0.82 & $\begin{array}{c}8.6 \\
(\text { Pyro }<10)\end{array}$ & $\begin{array}{c}0.56 \\
(\text { Pyro }>0.5)\end{array}$ & $\begin{array}{c}1.3 \\
(\text { Pyro }>1)\end{array}$ & $\begin{array}{c}0.39 \text { (Pyro }>0.35-0.5 \\
\text { vehicle combustion) }\end{array}$ \\
\hline \multicolumn{2}{|c|}{$\begin{array}{l}2014 \text { Mean Upwind Ratios } \\
\text { and Dominant Source }\end{array}$} & $\begin{array}{c}3.2 \\
(\text { Petro }>1)\end{array}$ & 0.83 & $\begin{array}{c}8.5 \\
(\text { Pyro }<10)\end{array}$ & $\begin{array}{c}0.66 \\
(\text { Pyro }>0.5)\end{array}$ & $\begin{array}{c}1.8 \\
(\text { Pyro }>1)\end{array}$ & $\begin{array}{c}0.42 \text { (Pyro }>0.35-0.5 \\
\text { vehicle combustion) }\end{array}$ \\
\hline
\end{tabular}

Acronym definitions: LMW = Low Molecular Weight; HMW = High Molecular Weight; PHN = Phenanthrene; ANT = Anthracene; FLA = Fluoranthene; $\mathrm{PYR}=$ Pyrene; $\mathrm{BaA}=$ Benzo[a] Anthracene; $\mathrm{CHR}=$ Chrysene.

were not detected at 14 of the 15 sites collected in 2011 and therefore, were not included in the diagnostic ratio analysis [19] [48] [49].

The PAH diagnostic ratios for the 2014 air samples also indicated a combination of both petrogenic and pyrogenic sources depending on the ratio (Table 1). Similar to the 2011 samples, the low molecular weight to the high molecular weight compounds (LMW/HMW > 1) at all of the 2014 sites indicated a dominant petrogenic source. Phenanthrene to phenanthrene plus anthracene $[\mathrm{PHN} /(\mathrm{PHN}+$ ANT)] suggested a combination of petrogenic and pyrogenic sources with potential influences from crude oil $(\mathrm{PHN} /(\mathrm{PHN}+\mathrm{ANT})=\sim 0.98)$, used motor oil $[\mathrm{PHN} /(\mathrm{PHN}+\mathrm{ANT})=\sim 0.78]$ and gasoline vehicle emissions $[\mathrm{PHN} /(\mathrm{PHN}+$ ANT $)=\sim 0.77 \pm 12]$. Similar to the 2011 air samples, the fluoranthene to fluoranthene plus pyrene $[\mathrm{FLA} /(\mathrm{FLA}+\mathrm{PYR})>0.5]$ ratios suggested a pyrogenic source of grass, wood or coal combustion ( $>0.5)$, fluoranthene to pyrene (FLA/PYR $>1$ ) suggested a pyrogenic source mainly of coal combustion and benzo[a]chrysene to benzo[a]chrysene plus chrysene $(\mathrm{BaA} /(\mathrm{BaA}+\mathrm{CHR})>0.35)$ indicated combustion as a source.

As a result, the diagnostic ratios used in this study, suggested both petrogenic and pyrogenic sources. The LMW/HMW, PHN/(PHN + ANT), and the PHN/ANT ratios all indicated a dominance of a petrogenic source for all of the 2011 sites in this study. The PHN/(PHN + ANT) ratio for all the 2011 sites were between 0.96 and 0.98 which are close to the values found for crude oil (0.98) [45]. In addition, the ratios for FLA/(FLA + PYR), FLA/PYR and $\mathrm{BaA} /(\mathrm{BaA}+\mathrm{CHR})$ indicated the presence of pyrogenic (i.e. coal) and combustion sources. Similarly, the diagnostic ratios calculated for all the 2014 sites indicated a combination of petrogenic and pyrogenic sources. It is also important to note, that interpreting diagnostic ratios should be done with caution as values may change with envi- 
ronmental fate as well as with vapor and particulate phases.

Factor Analysis and Principal Components Analysis. The factor analysis and principal components revealed three factors or potential emission sources for the 2011 air samples, explaining 89\% of the variance in the dataset (Figure 7). Factor 1 accounted for $73 \%$ of the variance, followed by factor 2 accounting for $10 \%$ and factor 3 accounting for $6 \%$ of the variance. The indicatory PAHs identified in factor 1 accounting for $73 \%$ of the total variance in the dataset were acenaphthylene, acenaphthene, fluorene, dibenzothiophene, phenanthrene, anthracene and pyrene. A previous study investigating $\mathrm{PAH}$ emissions from various industrial stacks in Taiwan had identified acenaphthylene, acenaphthene and anthracene as the indicatory PAHs of a cement plant [51]. Additionally, fluorene, phenanthrene, anthracene and pyrene are also considered predominant coal combustion tracers [47] [52]. Factor 2 accounts for $10 \%$ of the variance and is heavily weighted with benzo[b]fluoranthene, benzo[k]fluoranthene, benzo[a]pyrene, indeno[1,2,3-cd]pyrene and benzo[g,h,i]perylene, all of which have been associated with vehicle emissions. Factor 3, which accounts for $6 \%$ had only one dominate PAH, dibenzo[a,h]anthracene. Dibenzo[a]anthracene has been previously associated with vehicle emissions; however by itself, it may not have a specific source meaning [47].

Although there is no known source of coal combustion on the island, the refinery not only produces asphalt $(<1 \%)$ but its utilities are mainly fueled by asphalt, more commonly referred to as bitumen [53]. The differences between bitumen and coal can be characterized by not only there PAH concentrations but also there compositional signature. Greater proportions of alkylated phenanthrene homologues, as well as the more stable isomers, chrysene, benzo[e]pyrene or benzo[g,h,i]perylene are commonly found in petrogenic PAH sources such as crude oil, bitumen and asphalt. In contrast, pyrogenic PAHs, such as coal tar, tend to be dominated by phenanthrene, fluoranthene, pyrene and a greater proportion of the less stable isomers, benzo[a]anthracene, benzo[a]pyrene and indeno[1,2,3-cd]pyrene [48] [54]. Therefore, the refinery's asphalt fuel source may help to explain the factor loadings seen in the 2011 samples since they were dominated by indicatory PAH of petrogenic sources for crude oil, bitumen and asphalt (i.e. acenaphthylene, acenaphthene, anthracene, and pyrene). This is also supported by the $2011 \mathrm{BaA} /(\mathrm{BaA}+\mathrm{CHR})$ ratios observed $(0.21-0.59)$. Asphalt ratios have been reported to be between $0.16-0.39$ whereas coal tar has ratios between $0.51-0.56$.

The 2014 downwind and upwind sites revealed different factor loadings suggesting the influence of different emission sources. The factor analysis for the 2014 locations downwind of the refinery revealed four major factors or potential emission sources, explaining $89 \%$ of the variance. Factor 1 accounted for $44 \%$ of the contribution and was dominated by the low molecular weight compounds (fluorene, dibenzothiophene, phenanthrene and anthracene), suggesting petrogenic sources (Figure 7). Similar to the 2011 factor loadings, asphalt, cement, and coal indicator PAHs are also observed albeit to a lesser degree. Additional 

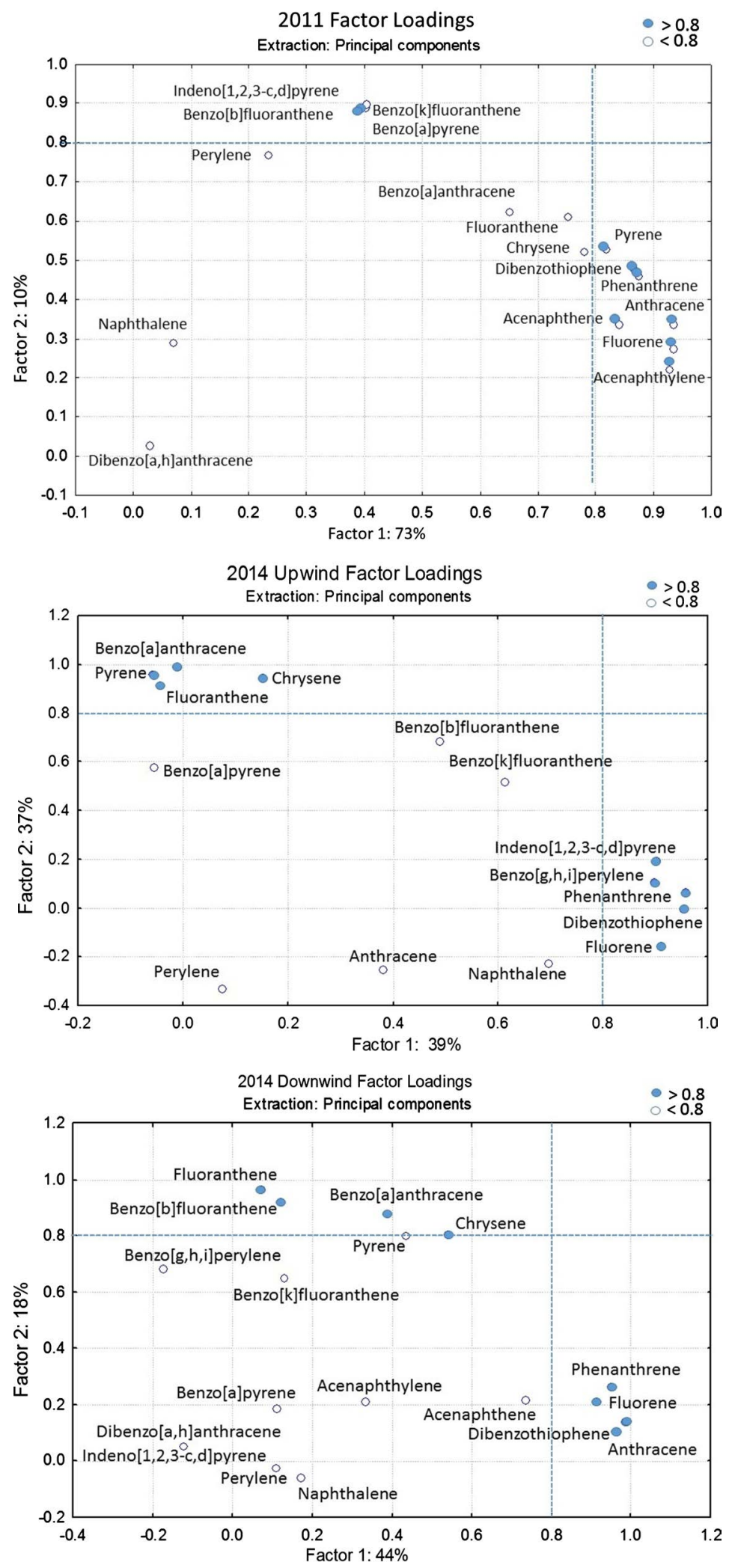

Figure 7. Factor loadings using principal components extraction from the 2011 and the 2014 ambient PAH concentrations in Curaçao. Solid circles represent those analytes with factor loadings $>0.80$ and indicate the significant PAHs for each factor that characterize the sampled area. 
influences are seen in factors 2 - 4 with the signals from petrogenic (i.e. fluoranthene) as well as the high molecular weight PAHs associated with pyrogenic sources. Factor 3, accounting for $15 \%$, is dominated by indeno[1,2,3-cd]pyrene and dibenzo[a] [h] anthracene. Factor 4 , accounting for $12 \%$, is dominated by benzo[a]pyrene and perylene. Indeno[1,2,3-cd]pyrene and dibenzo[a] [h]anthracene are typically associated with vehicle emissions and benzo[a]pyrene has been associated with both vehicle emissions and oil combustion [47].

In contrast, the upwind sites sampled in 2014 revealed only 2 factors explaining $77 \%$ of the variance. The two factors 1 and 2, accounted for 39\% and 37\%, respectively, suggesting a relatively homogeneous mixture of emission sources (Figure 7). Factor 1 was dominated by the low molecular weight compounds (fluorene, dibenzothiophene, phenanthrene) indicative of petrogenic sources as well as pyrogenic sources (i.e. indeno[1,2,3-cd]pyrene). Benzo[g,h,i]perylene was also a dominant indicator PAH in factor 1 and has been associated with both pyrogenic (e.g. vehicle emissions) as well as petrogenic sources (e.g. crude oil, bitumen, asphalt). Factor 2 is dominated by fluoranthene, pyrene, benzo[a]anthracene and chrysene. Fluoranthene, pyrene and chrysene are indicative of coal combustion and benzo[a]anthracene is indicative of oil combustion.

\section{Conclusion}

In general, ambient $\mathrm{PAH}$ concentrations in Curaçao were consistent with other urban and industrialized regions of the world; however, the levels measured downwind of the Isla Refineriá petrochemical complex were among some of the highest reported ambient PAHs globally. The mean ambient PAH levels downwind of the refinery were significantly higher than those located upwind with no temporal differences between 2011 and 2014. Source characterization through the use of concentration and distribution profiles, binary diagnostic ratios and factor analysis revealed both petrogenic (i.e. refinery) and pyrogenic (i.e. vehicular) emission sources. The sources of ambient PAHs downwind of Isla Refineriá were dominated by petrogenic emission sources and to a lesser degree pyrogenic emissions, whereas, the upwind locations appear to be equally influenced by both petrogenic and pyrogenic emissions sources. To our knowledge, this is the first study quantifying ambient levels of PAHs in Curaçao, which will be assist regulatory agencies and public health officials in elucidating emission sources and assessing potential human health risks associated with petrochemicals.

\section{Acknowledgements}

The authors wish to thank the Environmental Fund Netherlands Antilles (MINA Fund) and Mote Marine Laboratory for the financial support of this work. We are most grateful to George Keiffer (Curaçao Sea Aquarium), Gerard VanBuurt, Tone Moller (Avila Hotel) and the residents of Curaçao for the logistical support and for providing valuable insights and local knowledge to help us understand 
some of the societal issues and impacts from Isla Refineriá on local communities.

\section{Conflicts of Interest}

The authors declare no conflicts of interest regarding the publication of this paper.

\section{References}

[1] UNEP (1999) Assessment of Land-based Sources and Activities Affecting the Marine, Coastal and Associated Freshwater Environment in the Wider Caribbean Region. United Nations Environment Programme, Kingston, 125.

[2] UNEP-UCR/CEP (2010) Updated CEP Technical Report No. 33 Land-Based Sources and Activities in the Wider Caribbean Region. United Nations Environment Programme, Kingston.

[3] UNEP (1994) Regional Overview of Land-Based Sources of Pollution in the Wider Caribbean Region. UNEP Caribbean Environment Programme, Kingston.

[4] DCLP SEI a Helping Hand for Environmental Requirements Smoc. http://www.dutchcaribbeanlegalportal.com/news/latest-news/118-sei-a-helping-han d-for-environmental-requirements-smoc

[5] Van der Torn, P. (1999) Health Complaints \& Air Pollution from the Isla refinery in Curacao. Public Health Service of Rotterdam and Surrounding.

[6] USONA (2008) Nature and Environment as Assets. Evaluation of the NEPP 2004-2007. The Implementation Organisation of the Foundation for Development of the Netherland Antilles.

[7] Samet, J.M. (2007) Traffic, Air Pollution, and Health. Inhalation Toxicology, 19, 1021-1027. https://doi.org/10.1080/08958370701533541

[8] White, R.H., et al. (2005) Report of Workshop on Traffic, Health, and Infrastructure Planning. Archives of Environmental \& Occupational Health, 60, 70-76. https://doi.org/10.3200/AEOH.60.2.70-76

[9] Pulster, E.L. (2015) Assessment of Public Health Risks Associated with Petrochemical Emissions Surrounding an Oil Refinery. Public Health, University of South Florida, Tampa, FL.

[10] Shoeib, M. and Harner, T. (2002) Characterization and Comparison of Three Passive Air Samplers for Persistent Organic Pollutants. Environmental Science \& Technology, 36, 4142-4151. https://doi.org/10.1021/es020635t

[11] Melymuk, L., et al. (2011) Evaluation of Passive Air Sampler Calibrations: Selection of Sampling Rates and Implications for the Measurement of Persistent Organic Pollutants in Air. Atmospheric Environment, 45, 1867-1875. https://doi.org/10.1016/j.atmosenv.2011.01.011

[12] Harner, T., et al. (2013) Calibration and Application of PUF Disk Passive Air Samplers for Tracking Polycyclic Aromatic Compounds (PACs). Atmospheric Environment, 75, 123-128. https://doi.org/10.1016/j.atmosenv.2013.04.012

[13] Bohlin, P., Jones, K.C. and Strandberg, B. (2010) Field Evaluation of Polyurethane Foam Passive Air Samplers to Assess Airborne PAHs in Occupational Environments. Environmental Science \& Technology, 44, 749-754. https://doi.org/10.1021/es902318g

[14] He, J. and Balasubramanian, R. (2010) A Comparative Evaluation of Passive and Active Samplers for Measurements of Gaseous Semi-Volatile Organic Compounds 
in the Tropical Atmosphere. Atmospheric Environment, 44, 884-891. https://doi.org/10.1016/j.atmosenv.2009.12.009

[15] Comrey, L.A. and Lee, H.B. (1992) A First Course in Factor Analysis. 2nd Edition, Lawrence Erlbaum Associates, Hillside.

[16] Tabachnick, B.G. and Fidell, L.S. (2007) Using Multivariate Statistics. 5th Edition, Allyn \& Bacon, Boston.

[17] Yong, A.G. and Pearce, S. (2013) A Beginner's Guide to Factor Analysis: Focusing on Exploratory Factor Analysis. Tutorials in Quantitative Methods for Psychology, 9, 79-94. https://doi.org/10.20982/tqmp.09.2.p079

[18] MacCallum, R.C., Widaman, K.F., Zhang, S. and Hong, S. (1999) Sample Size in Factor Analysis. Psychological Methods, 4, 84-99. https://doi.org/10.1037/1082-989X.4.1.84

[19] Ravindra, K., Sokhi, R. and Van Grieken, R. (2008) Atmospheric Polycyclic Aromatic Hydrocarbons: Source Attribution, Emission Factors and Regulation. Atmospheric Environment, 42, 2895-2921. https://doi.org/10.1016/j.atmosenv.2007.12.010

[20] Sanhueza, E., Africano, M. and Romero, J. (1982) Air Pollution in Tropical Areas. Science of the Total Environment, 23, 3-10. https://doi.org/10.1016/0048-9697(82)90115-2

[21] Pulster, E.L., Johnson, G., Hollander, D., McCluskey, J. and Harbison, R. (2018) Exposure Assessment of Ambient Sulfur Dioxide Downwind of an Oil Refinery in Curaçao. Journal of Environmental Protection, 9, 194-210. https://doi.org/10.4236/jep.2018.93014

[22] Callén, M.S., Iturmendi, A. and López, J.M. (2014) Source Apportionment of Atmospheric PM2.5-Bound Polycyclic Aromatic Hydrocarbons by a PMF Receptor Model. Assessment of Potential Risk for Human Health. Environmental Pollution, 195, 167-177. https://doi.org/10.1016/j.envpol.2014.08.025

[23] Jaward, F.M., Farrar, N.J., Harner, T., Sweetman, A.J. and Jones, K.C. (2004) Passive Air Sampling of Polycyclic Aromatic Hydrocarbons and Polychlorinated Naphthalenes across Europe. Environmental Toxicology and Chemistry, 23, 1355-1364. https://doi.org/10.1897/03-420

[24] Degrendele, C., et al. (2014) Size Specific Distribution of the Atmospheric Particulate PCDD/Fs, dl-PCBs and PAHs on a Seasonal Scale: Implications for Cancer Risks from Inhalation. Atmospheric Environment, 98, 410-416. https://doi.org/10.1016/j.atmosenv.2014.09.001

[25] Pandit, G.G., Sahu, S.K., Puranik, V.D. and Venkat Raj, V. (2006) Exchange of Polycyclic Aromatic Hydrocarbons across the Air-Water Interface at the Creek Adjoining Mumbai Harbour, India. Environment International, 32, 259-264. https://doi.org/10.1016/j.envint.2005.08.021

[26] Motelay-Massei, A., et al. (2005) Using Passive Air Samplers to Assess Urban-Rural Trends for Persistent Organic Pollutants and Polycyclic Aromatic Hydrocarbons. 2. Seasonal Trends for PAHs, PCBs, and Organochlorine Pesticides. Environmental Science \& Technology, 39, 5763-5773. https://doi.org/10.1021/es0504183

[27] Kaya, E., et al. (2012) Spatial and Temporal Variation and Air-Soil Exchange of Atmospheric PAHs and PCBs in an Industrial Region. Atmospheric Pollution Research, 3, 435-449. https://doi.org/10.5094/APR.2012.050

[28] Zhu, Y., et al. (2015) Indoor/Outdoor Relationships and Diurnal/Nocturnal Variations in Water-Soluble Ion and PAH Concentrations in the Atmospheric PM2.5 of a Business Office Area in Jinan, a Heavily Polluted City in China. Atmospheric Re- 
search, 153, 276-285.

https://doi.org/10.1016/j.atmosres.2014.08.014

[29] Birgul, A. and Tasdemir, Y. (2015) Concentrations, Gas-Particle Partitioning, and Seasonal Variations of Polycyclic Aromatic Hydrocarbons at Four Sites in Turkey. Archives of Environmental Contamination and Toxicology, 68, 46-63. https://doi.org/10.1007/s00244-014-0105-8

[30] Odabasi, M., et al. (1999) Polycyclic Aromatic Hydrocarbons (PAHs) in Chicago Air. Science of the Total Environment, 227, 57-67. https://doi.org/10.1016/S0048-9697(99)00004-2

[31] Devi, N.L., Qi, S. and Yadav, I.C. (2014) Atmospheric Polycyclic Aromatic Hydrocarbons (PAH) in Manipur of the Northeast India: Monitoring on Urban, Rural, and Mountain Sites. Polycyclic Aromatic Compounds, 34, 12-34. https://doi.org/10.1080/10406638.2013.839455

[32] Wei, C., et al. (2015) Occurrence, Gas/Particle Partitioning and Carcinogenic Risk of Polycyclic Aromatic Hydrocarbons and Their Oxygen and Nitrogen Containing Derivatives in Xi'an, Central China. Science of The Total Environment, 505, 814-822. https://doi.org/10.1016/j.scitotenv.2014.10.054

[33] El-Mubarak, A.H., et al. (2015) Occurrence of High Levels of Persistent Organic Pollutants (POPs) in Particulate Matter of the Ambient Air of Riyadh, Saudi Arabia. Arabian Journal for Science and Engineering, 40, 81-92. https://doi.org/10.1007/s13369-014-1485-9

[34] De Pieri, S., et al. (2014) PAHs in the Urban Air of Sarajevo: Levels, Sources, Day/Night Variation, and Human Inhalation Risk. Environmental Monitoring and Assessment, 186, 1409-1419. https://doi.org/10.1007/s10661-013-3463-1

[35] Trasande, L., et al. (2015) Polycyclic Aromatic Hydrocarbons, Brachial Artery Distensibility and Blood Pressure among Children Residing Near an Oil Refinery. Environmental Research, 136, 133-140. https://doi.org/10.1016/j.envres.2014.08.038

[36] Ravindra, K., et al. (2006) Seasonal and Site-Specific Variation in Vapour and Aerosol Phase PAHs over Flanders (Belgium) and Their Relation with Anthropogenic Activities. Atmospheric Environment, 40, 771-785. https://doi.org/10.1016/j.atmosenv.2005.10.011

[37] Tobiszewski, M. and Namiesnik, J. (2012) PAH Diagnostic Ratios for the Identification of Pollution Emission Sources. Environmental Pollution, 162, 110-119. https://doi.org/10.1016/j.envpol.2011.10.025

[38] Slezakova, K., et al. (2013) Impact of Vehicular Traffic Emissions on Particulate-Bound PAHs: Levels and Associated Health Risks. Atmospheric Research, 127, 141-147. https://doi.org/10.1016/j.atmosres.2012.06.009

[39] Slezakova, K., et al. (2013) PAH Air Pollution at a Portuguese Urban Area: Carcinogenic Risks and Sources Identification. Environmental Science and Pollution Research, 20, 3932-3945. https://doi.org/10.1007/s11356-012-1300-7

[40] Teixeira, E.C., et al. (2013) Polycyclic Aromatic Hydrocarbons Study in Atmospheric Fine and Coarse Particles Using Diagnostic Ratios and Receptor Model in Urban/Industrial Region. Environmental Monitoring and Assessment, 185, 9587-9602. https://doi.org/10.1007/s10661-013-3276-2

[41] Pies, C., Ternes, T.A. and Hofmann, T. (2008) Identifying Sources of Polycyclic Aromatic Hydrocarbons (PAHs) in Soils: Distinguishing Point and Non-Point Sources Using an Extended PAH Spectrum and N-Alkanes. Journal of Soils and Sediments, 8, 312-322. https://doi.org/10.1007/s11368-008-0031-3

[42] Sporstol, S., et al. (1983) Source Identification of Aromatic Hydrocarbons in Sedi- 
ments Using GC/MS. Environmental Science \& Technology, 17, 282-286. https://doi.org/10.1021/es00111a008

[43] Wang, Z., Stout, S.A. and Fingas, M. (2006) Forensic Fingerprinting of Biomarkers for Oil Spill Characterization and Source Identification. Environmental Forensics, 7, 105-146. https://doi.org/10.1080/15275920600667104

[44] Douglas, G.S., Emsbo-Mattinglym S.D., Stout, S.A., Uhler, A.D. and McCarthy, K.J. (2015) Hydrocarbon Fingerprinting Methods. In: Murphy, B.L. and Morrison, R.D., Eds., Introduction to Environmental Forensics, Academic Press, San Diego, 201-309. https://doi.org/10.1016/B978-0-12-404696-2.00008-4

[45] Sicre, M.A., et al. (1987) Aliphatic and Aromatic Hydrocarbons in Different Sized Aerosols over the Mediterranean Sea: Occurrence and Origin. Atmospheric Environment, 21, 2247-2259. https://doi.org/10.1016/0004-6981(87)90356-8

[46] Budzinski, H., Jones, I., Bellocq, J., Piérard, C. and Garrigues, P. (1997) Evaluation of Sediment Contamination by Polycyclic Aromatic Hydrocarbons in the Gironde Estuary. Marine Chemistry, 58, 85-97. https://doi.org/10.1016/S0304-4203(97)00028-5

[47] Zhang, W., et al. (2008) Source Diagnostics of Polycyclic Aromatic Hydrocarbons in Urban Road Runoff, Dust, Rain and Canopy Throughfall. Environmental Pollution, 153, 594-601. https://doi.org/10.1016/j.envpol.2007.09.004

[48] Yunker, M.B., et al. (2002) PAHs in the Fraser River Basin: A Critical Appraisal of $\mathrm{PAH}$ Ratios as Indicators of PAH Source and Composition. Organic Geochemistry, 33, 489-515. https://doi.org/10.1016/S0146-6380(02)00002-5

[49] Katsoyiannis, A., Terzi, E. and Cai, Q.-Y. (2007) On the Use of PAH Molecular Diagnostic Ratios in Sewage Sludge for the Understanding of the PAH Sources. Is This Use Appropriate? Chemosphere, 69, 1337-1339. https://doi.org/10.1016/j.chemosphere.2007.05.084

[50] Kim, D., Kumfer, B.M., Anastasio, C., Kennedy, I.M. and Young, T.M. (2009) Environmental Aging of Polycyclic Aromatic Hydrocarbons on Soot and Its Effect on Source Identification. Chemosphere, 76, 1075-1081. https://doi.org/10.1016/j.chemosphere.2009.04.031

[51] Yang, H.H., Lee, W.-J., Chen, S.-J. and Lai, S.-O. (1998) PAH Emission from Various Industrial Stacks. Journal of Hazardous Materials, 60, 159-174. https://doi.org/10.1016/S0304-3894(98)00089-2

[52] Simcik, M.F., Eisenreich, S.J. and Lioy, P.J. (1999) Source Apportionment and Source/Sink Relationships of PAHs in the Coastal Atmosphere of Chicago and Lake Michigan. Atmospheric Environment, 33, 5071-5079. https://doi.org/10.1016/S1352-2310(99)00233-2

[53] Van der Auweraert, R.J.K., Hoekstra, B. and Koopmans, G. (2001) Environmental Study Downwind of the Schottegat Industrial Area. The Netherlands via Noodprogramma 1998, Willemstad, 84.

[54] Ahrens, M.J. and Depree, C.V. (2010) A Source Mixing Model to Apportion PAHs from Coal Tar and Asphalt Binders in Street Pavements and Urban Aquatic Sediments. Chemosphere, 81, 1526-1535.

https://doi.org/10.1016/j.chemosphere.2010.08.030 